\title{
ASSESSMENT OF UMBILICAL CORD BLOOD IRON AND TIBC LEVELS IN NEONATES OF ANAEMIC MOTHERS
}

Dr. Durdana Sayeed, Dr. Ghouse M Ali, Dr. Arshiya Masood Osmani, Dr. Rohini N.

Dr. MD. Siddique Ahmed Khan.

1. Assistant Professor, Department of Biochemistry, Dr. VRK Women's Medical College \& Allied Hospitals, Hyderabad.

2. Professor and HOD, Department of Biochemistry, Dr. VRK Women's Medical College \& Allied Hospitals, Hyderabad.

3. Assistant Professor, Department of Biochemistry, Dr. VRK Women's Medical College \& Allied Hospitals, Hyderabad.

4. Assistant Professor, Department of Biochemistry, Dr. VRK Women's Medical College \& Allied Hospitals, Hyderabad.

5. Associate Professor, Department of Biochemistry, Dr. VRK Women's Medical College \& Allied Hospitals, Hyderabad.

\section{CORRESPONDING AUTHOR}

Dr. Durdana Sayeed,

H.NO-10-1-128/1/2/E,

"ALIMANOR" MASAB TANK,

Hyderabad. AP-500028,

E-mail: drdurdanasayeed@gmail.com,

Ph: 9848502341/9866226286.

ABSTRACT: The most common cause of anaemia in pregnancy is Iron deficiency which can affect the newborns. This study was done to compare the serum Iron \& Total Iron Binding Capacity (TIBC) levels in the 20 newborns of non-anaemic and anaemic mothers each.

Results showed that Haemoglobin \% was significantly lower ( $\mathrm{P} \leq 0.001)$ in newborns of anaemic mothers. Serum Iron levels did not show any significant difference $(P=0.1) \&$ TIBC levels were significantly higher $(\mathrm{P} \leq 0.01)$ in newborns of anaemic mothers as compared to newborns of non- anaemic mothers.

KEYWORDS: Umbilical Cord blood, Iron deficiency anaemia, pregnancy, Serum Iron, S. TIBC.

INTRODUCTION: Anaemia is one of the most common conditions prevalent in our country. The most common cause of anaemia in pregnancy is Iron deficiency.

WHO defines anaemia in pregnancy when $\mathrm{Hb} \%$ is $\leq 11 \mathrm{gm} / \mathrm{dl}^{1}$.

$\mathrm{Hb} \% \leq 11 \mathrm{gm} / \mathrm{dl}$ especially in late pregnancy should be considered abnormal and due to Iron deficiency rather than due to hypovolemia of pregnancy ${ }^{2}$.

The mean $\mathrm{Hb}$ level in cord blood is $13.5-20.5 \mathrm{gm} / \mathrm{dl}$ and $\mathrm{Hb} \% \leq 14 \mathrm{gm} / \mathrm{dl}$ at birth is considered abnormal2 ${ }^{2}$.

AIM: This study was done to compare the Haemoglobin, serum Iron \& TIBC levels in 20 newborns of non-anaemic mothers and anaemic mothers each.

MATERIALS \& METHODS: The study done by the approval of ethical committee of Dr. VRKWMC, Teaching Hospital \& Research Centre. The study group is comprised of 20 pregnant women without anaemia and their 20 newborns (Group I). The control group included 20 pregnant women with anaemia (Hb levels $<10 \mathrm{gm} / \mathrm{dl}$ ) and their 20 newborns (Group II). Cord 
blood was collected from the newborns' end of the umbilical cord within 5 minutes of the delivery.

FOR ESTIMATION OF HAEMOGLOBIN - We followed Cyanmethaemoglobin method ${ }^{3}$. FOR ESTIMATION OF SERUM IRON \& TIBC - We followed Dipyridyl method 4 .

The instrument used was Spectrophotometer (Elico sl 159).

\section{RESULTS:}

TABLE I-SHOWING Hb, IRON AND TIBC LEVELS IN NEWBORNS OF NON-ANAEMIC MOTHERS (GROUP I)

\begin{tabular}{|l|l|l|l|}
\hline & Hb in gm\% & S. Fe in ugm\% & TIBC ugm\% \\
\hline MEAN & 14.7 & 107.5 & $\mathbf{2 5 6 . 3}$ \\
S. D +/_ & 0.91 & 30.61 & $\mathbf{1 1 4 . 0 4}$ \\
S.E +/_ & $\mathbf{0 . 2}$ & $\mathbf{6 . 8 4}$ & $\mathbf{2 5 . 4}$ \\
\hline
\end{tabular}

TABLE II - SHOWING Hb, IRON and TIBC LEVELS IN NEW BORNS OF ANAEMIC MOTHERS (GROUP II)

\begin{tabular}{|l|l|l|l|}
\hline & Hb in gm\% & S. Fe in ugm\% & TIBC ugm\% \\
\hline MEAN & 12.6 & 99.7 & 301.45 \\
\hline S.D +/_ & 0.96 & 34 & 56.31 \\
\hline S.E +/_ & 0.22 & & \\
\hline
\end{tabular}

TABLE III - COMPARISSION of Hb, IRON AND TIBC LEVELS B/W GROUPS I \& II

\begin{tabular}{|c|l|l|l|}
\hline & Hb in gm $\%$ & S. Fe in ugm $\%$ & TIBC ugm\% \\
\hline t-value & 6.93 & 0.76 & $\mathbf{1 . 5 9}$ \\
p-value & $<0.001$ & $=0.1$ & $\leq \mathbf{0 . 0 1}$ \\
Df & $\mathbf{3 8}$ & $\mathbf{3 8}$ & $\mathbf{3 8}$ \\
\hline
\end{tabular}

The stastical analysis done was done using SAS Version of software.

Newborns of anaemic mothers showed

I. Significantly lower levels of $\mathrm{Hb}(\mathrm{P}<0.001)$ when compared to newborns of non anaemic mothers.

II. Serum Iron did not show any significant difference $(P=0.1)$.

III. Serum TIBC levels were significantly higher $(\mathrm{P} \leq 0.01)$ in New borns of anaemic mothers as compared to new borns of non- anaemic mothers. 
DISCUSSION: In our study comparison of newborns of non-anaemic and anaemic mothers showed

- Haemoglobin of Group I is $14.7 \mathrm{gm} \%$ and that of Group II is $12.6 \mathrm{gm} \%$ with p value $(<0.001)$.

- Serum Iron showed Group I is $107.5 \mu g m / d l$ and that of Group II is $99.7 \mu g m / d l$ with $p$ value $(=0.1)$.

- Serum TIBC of Group I is $256.3 \mu \mathrm{gm} / \mathrm{dl}$ and that of Group II is $301.45 \mu \mathrm{gm} / \mathrm{dl}$ with $\mathrm{p}$ ( $\leq$ 0.01).

A significant difference in all parameters except SERUM IRON reflects the metabolic demands created by the foetus for erythropoiesis and foetus draws its full requirement from the mother.

Iron deficiency anaemia in mother is considered as a risk factor for Iron deficiency in infancy 5,6 Chitra Upadhyaya et $\mathrm{al}^{7}$, found that there was a significant decrease in $\mathrm{Hb} \%$ in the new borns of anaemic groups when compared to the newborns of nonanaemic mothers. Similarly serum iron levels was also having a significant difference. Where as in our study there is no significant difference in serum iron levels.

TABLE IV - COMPARISSION B/W REFERENCE STUDY \& OUR STUDY

\begin{tabular}{|l|l|l|l|}
\hline $\begin{array}{l}\text { NEWBORNSOFANAEMIC } \\
\text { MOTHERS }\end{array}$ & Hb in gm\% & S.IRON $(\mu \mathrm{gm} / \mathrm{dl})$ & TIBC $(\mu \mathrm{gm} / \mathrm{dl})$ \\
\hline REFERENCE STUDY & 14.9 & 108.0 & 288.9 \\
\hline OUR STUDY NON- & 14.7 & 107.5 & 256.3 \\
\hline $\begin{array}{l}\text { NEWBORNS OF NOSO } \\
\text { ANAEMIC MOTHERS }\end{array}$ & & & \\
\hline REFERENCE STUDY & 13.1 & 76.7 & 332.8 \\
\hline OUR STUDY & 12.6 & 99.7 & 301.45 \\
\hline
\end{tabular}

CONCLUSION: Compared to previous study7, our study shows that serum iron does not show any significant difference in the newborns of non-anaemic and anaemic mothers, whereas $\mathrm{Hb} \&$ TIBC showing significant difference.

In the socio-economic conditions of our country, people are scared of nutritional deficiency for the newborn children. But it has been observed in our study that the newborns of anaemic mothers have no iron deficiency inspite of being born to anaemic mothers.

\section{LIMITATIONS OF THE STUDY:}

i) Samples for study has to be collected only from those cases which are delivered before noon, because S.iron levels show a diurnal variation-S.iron levels decline by almost 50\% from 8:00 to 14:00 hours.

ii) Sample collection from umbilical cord fails, if there is delay in drawing the sample. 
ACKNOWLEDGMENT: We are extremely thankful to Dr. SARIB RASOOL KHAN - Managing Director DR. V R K WMC, Teaching Hospital \& Research Centre and Allied Hospitals, for providing all the facilities for the research work.

Our sincere thanks to Dr. SIKANDER HUSSAIN - Professor -Dept. of Physiology for the cooperation.

\section{REFERENCES:}

1. Saraiya.Rao.Chatterjee,Principles of Obs and Gyn forPGs , $2^{\text {nd }}$ edition pg-33.

2. Williams, Obstetrics-21st Edn.

3. Harold Varley, Practical Clinical Biochemistry, $4^{\text {th }}$ Edn ,pg no.585.

4. Harold Varley, Practical Clinical Biochemistry, $4^{\text {th }}$ Edn. pg no. 472.

5. Kilbride, J., Baker,T.G., Parapia, L.A.,Khoury,S.A..Shuqaidef, S.W., \& Jerwood, D.Anaemia During Pregnancy as a Risk Factor for Iron Defeciency Anaemia in infancy. Int J Epidemiol (1999) 28: 461- 468.

6. J. Colomer, C. colomer ,D. Gutierrez, A. Jubert A. Nolosaco, J. Donat, R.Fernandez- Delgado, F. Donat and C. Alavarez- Dardet. Anaemia During Pregnancy as a Risk Factor for Infant Iron Deficiency. Paediatric \& Perinatal Epidemiology 1990,4 (2).196 - 204.

7. Chitra Upadhyaya et al, Serum Iron, copper \& Zinc status in Maternal \& Cord blood, IJCB , 2004, $48-52$. 